\title{
Investigation of Long Shaft Failure in John Deere 955 Grain Combine Harvester under Static Load
}

\author{
Mohsen Azadbakht", Mostafa Esmaili Shayan, Hassan Jafari \\ Department of Agricultural Machinery Engineering, Gorgan University of Agricultural Sciences and Natural Resources, Gorgan, Iran \\ *Corresponding author: azadbakht@gau.ac.ir
}

Copyright (C) 2013 Horizon Research Publishing All rights reserved.

\begin{abstract}
Shaft in combine is one of the most important components of transformer of power to the wheels. One of the main failures in combines is breaking shaft which repairmen refer it. For analyzing stress, a typical sample from a type of combine was selected, called JD955 combine. Long shaft in this combine was analyzed with finite element method by the generic package of Ansys 13 under static load. Conducted analysis showed that there is a maximum stress in contact surfaces of indentations and also in place of changing diameter. Safety factor value is low in parts of the shaft and this increases the probability of failure at these points.
\end{abstract}

Keywords Ansys, Shaft, Stress, Grain Combine harvester, Finite element, Failure

\section{Introduction}

Iranian combine-building company is the largest Iranian company which produces combine. This company is committed to promotion and competition in national market and following the process of product development, its goals are as follows: Maximum product quality and reliability; customer satisfaction and the reduction of time of development and cost. An important issue for today industrial companies is how to reduce time and cost of developing a new product [3]. Accordingly, they tried to use large capacity of memory in computer, fast processing speed, user-friendly products and attractive shape for enabling to interact with each other. In other words, they must have specific engineering. This action help to reduce product task and consequently cost, and time of developing product will decrease. Computer aided design, computer aided manufacturing and computer aided engineering are the technologies which are used for this purpose during the production cycle [6]. Iranian combine - building company has been produced 955JD combine from past years in Iran. This company modifies current product to promote quality and product efficiency and reduce the time of product development. During correcting new product, some evolutions occurred such as increased capacity of holding tank of seed, using of longer evacuation pipe, increased engine power, adding driver's chamber equipments, usage of internal volume of front shaft as the compressed air tank etc [6]. Power transmission shaft to the wheels is a one of the main components in combine. Because this component is in charge of transmitting power to the wheels in any moment, it needs very well design to avoid breaking shaft in 955JD combine in practice.

Reference [2] designed 3D model of straw walker crankshaft in grain combine harvesters on Solid Works 2010 software then analyzed by using finite element method on Ansys Work Bench 11 software and obtained the maximum stresses and determined associated safety factor for maximum stresses. Reference [7] used experimental and numerical methods, for the stress analysis of a frontal truck axle beam, and the results verified with the finite element method which was graphical stress investigation. Researchers began empirical and numerical analysis in tractor frontal shaft. According to earned results from finite element method, redesign was done for weight reduction, optimization and easy to construction and then five different models was proposed based on ease of production and weight reduction. Earned results were based on finite element method and analysis was based on different ways which resulted in obtaining 13 test certificates [8]. Reference [9] used empirical and numerical approaches for design change from casting to coating based welding.

The main aim of this study is analyzing long shaft in 955JD combine under static loading and also surveying its mechanical strength under loading conditions and achieving to this point which under what circumstances it will be failed.

\section{Material and Methods}

While determining the exact location of the applied load on the components is very difficult, all vehicles are subject to static and dynamic loads. For achieving correct answer, it is necessary to ignore unnecessary parts that usually come with 
the components. Figure 1 shows the geometry of long shaft in JD 955 combine. This figure has been designed by Solid Works software.

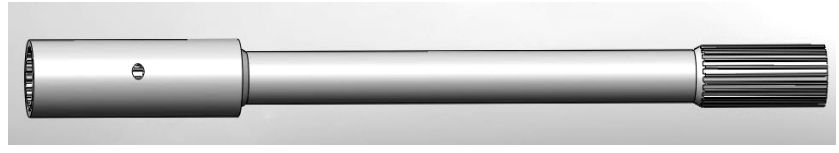

Figure 1. 3ds Model of axle of JD955.

\subsection{Static Load on Long Shaft}

Applied static load on shaft in JD955 combine is the torque which its main function is driving the wheels in combine. Figure 2 shows applied loads on shaft under static mode.

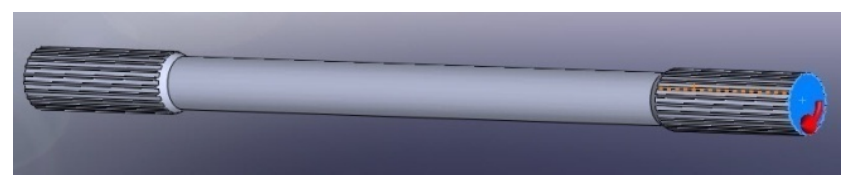

Figure 2. Forces acting on axle of JD955 in static displacements

\subsection{Stress Analysis}

Generic package ANSYS version 13 is one of the analysis software in finite element method for solving this problem. Geometric model was provided for left shaft and created 3D design. For comprehensive analysis of the shaft's components, bushing and its gears was included in 3D design and analysis. To achieve maximum accuracy, SOLID92 element was selected with 10 nodes [5]. Any node in SOLID92 element has 6 degrees of freedom which it can model very well regular networks [10]. The shaft in left wheel is provided by two-dimensional volumetric elements from SOLID82 element and 3D cube from SOLID92. Figure 3 shows 3D model of long shaft in JD955 combine with considering the elements. Average size of elements used in the analysis is $0.537 \mathrm{~mm}$. So finite element method of shaft in JD955 combine consist of 68758 elements and 205910 nodes.

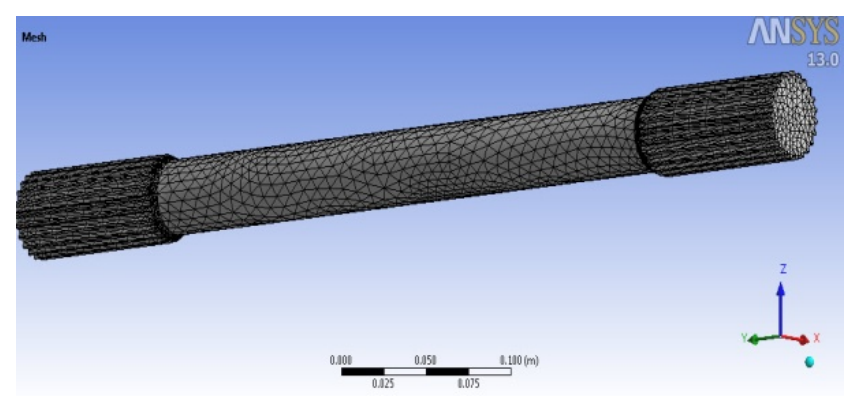

Figure 3. 3ds Meshed Model of axle of JD955 in ansys 13 software.

\subsection{Properties of Materials}

Torque transmission axis from the gearbox to the wheel (shaft) usually is built from $16 \mathrm{MnCr} 5$ alloy and
EN10084:2008 standard. Its mechanical and physical properties are provided in table 1 [12].

Table 1. Material data of axle of combine harvesting.

\begin{tabular}{ccc}
\hline Characteristic & Value & Unit \\
\hline Young's modulus & $\mathrm{E}=210000$ & $\mathrm{MPa}$ \\
Poisson's ratio & $v=0.3$ & - \\
Density & $\rho=7721^{3}$ & $\mathrm{~kg} / \mathrm{m}$ \\
Yield stress & $\sigma_{\mathrm{y}}=590$ & $\mathrm{MPa}$ \\
Tensile Strength & $\sigma=780$ & $\mathrm{MPa}$ \\
\hline
\end{tabular}

\subsection{Needed Power for Moving Combine}

Power is calculated from equation 1 [11].

$$
T=\frac{60000 \times P}{2 \times \pi \times n}
$$

Where, $\mathrm{p}=$ power and $\mathrm{n}=$ revolution per minute $(\mathrm{rpm})$

Revolution per minute is calculated using power transmission system from 4-piece belt in front of engine. Needed power is changed in terms of combine speed, rolling resistance of soil, combine weight and land slope. Maximum power can estimated with following assumptions: combine weight 10 ton, coefficient of rolling resistance against combine wheels 0.2 , actual average speed of working combine $2.5 \mathrm{~km} / \mathrm{h}$, slip (slipping wheels) $15 \%$ and flat land.

According to aforementioned assumptions, first, needed power on the axle of front wheels was calculated from equation 2. It equals $16 \mathrm{~kW}$.

$$
P_{\text {axle }}=\frac{W \times g \times f \times V}{3600}
$$

Where,

$\mathrm{P}_{\text {axle }}=$ Power on front wheel axle $(\mathrm{kW}), \mathrm{W}=$ Combine $\operatorname{mass}(\mathrm{kg}), \mathrm{g}=$ Acceleration of $\operatorname{gravity}\left(9.81 \mathrm{~m} / \mathrm{s}^{2}\right), \mathrm{f}=$ rolling resistance, $\mathrm{V}=$ Velocity $(\mathrm{km} / \mathrm{h})$

Then, $25 \%$ loss in power transmission system and $15 \%$ as loss in frictional power are included [4], so:

$$
\frac{16}{0.85 \times 0.75}=25 \mathrm{~kW}
$$

Therefore, needed power ratio for moving vehicle to total power in engine equal:

$$
\frac{25}{77.5} \times 100=32.25 \%
$$

Table 2. Rotational speeds in different parts of JD955.

\begin{tabular}{cccc}
\hline Catalog No. & Diameter(mm) & $(\mathrm{rpm})$ & Place \\
\hline AZ-25702 & 215 & 2500 & Engine head \\
H-11497 & 381 & $1041-2327$ & $\begin{array}{c}\text { Shaft head of } \\
\text { main clutch }\end{array}$ \\
\hline
\end{tabular}


The nominal power of engine in JD955 combine is 77.5 $\mathrm{kW}$ [4]. So needed power for moving vehicle will be $25 \mathrm{~kW}$. Also according to rotational speed in different parts of combine (table 2) and having power, the applied torque on axis is calculated by equation 1 . According to table 3 and regardless reduction in assistant gear (posi torque), the total ratio of round reduction in gears 1 and 4 is 173.4 and 21.6, respectively. So the rotational speed of axle in gears 1 and 4 is 14.41 and $115.74 \mathrm{rpm}$, respectively. According to equation 1 , applied torque on shaft for transmitting to the wheels is 16.56 kN.m. The minimum torque in gear 4 will equal 2.06 kN.m. Maximum stress range can be calculated with analyzing piece by finite element method and with given values. Where the maximum stress is applied, if piece be fragile, it will break. That is why designers are usually interested to know how much maximum yield strength is. Finally it will break, because after yield strength and the permanent deformation of piece toward failure. This theory is called distortion-energy which introduced by Von-Mises about flexible material in 1989 [13]. Von-Mises' stress is calculated by following equation:

$$
\sigma^{\prime}=\left[\frac{\left(\sigma_{1}-\sigma_{2}\right)^{2}+\left(\sigma_{2}-\sigma_{3}\right)^{2}+\left(\sigma_{1}-\sigma_{3}\right)^{2}}{2}\right]^{\frac{1}{2}}
$$

In equation $3, \sigma_{1}, \sigma_{2}$ and $\sigma_{3}$ equal to applied main stresses in three main axes.

Table 3. Revolution reduction ratios in Power Transitions of JD955.

\begin{tabular}{ccc}
\hline $\begin{array}{c}\text { Gear No. or } \\
\text { Place }\end{array}$ & $\begin{array}{c}\text { Speed range } \\
(\mathrm{km} / \mathrm{h})\end{array}$ & Revolution reduction ratio \\
\hline 1 & $1-2.4$ & 6.27 \\
4 & $8.5-20$ & 0.78 \\
Differential & - & 4.25 \\
Final Drive & - & 6.50 \\
\hline
\end{tabular}

\section{Results and Discussion}

Conducted analysis showed clearly that there is maximum stress in contact surfaces of all indentations and also in place of changing diameter. Figure 4 shows it.

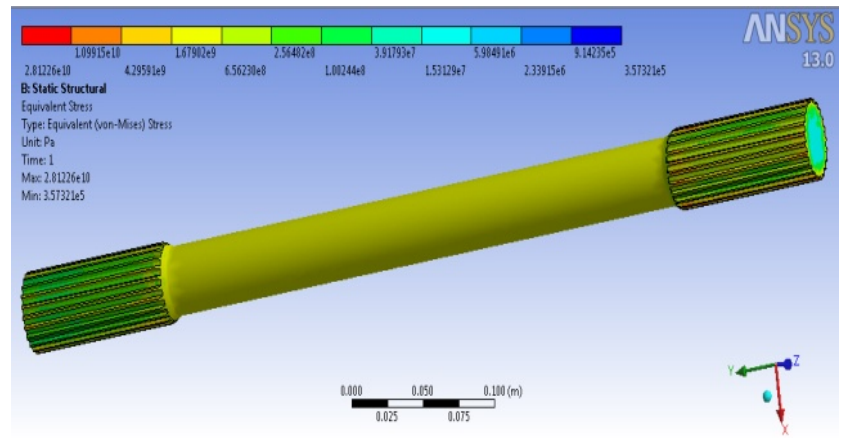

Figure 4. Von Misses stress contour in torsion loading of axle of JD955 in static loading.
According to distortion-energy, when allowable stress equals to yield stress, failure phenomenon will occur. So safety factor can be calculated by equation 4 via dividing yield limit stress to maximum Von-Mises' stress [14].

$$
n_{d}=\frac{S}{\tau}
$$

Where, $\mathrm{S}=$ strength to fail, $\tau=$ allowable stress

Figures 5 and 6 show conducted analysis by ANSYS13 software for estimating safety factor value. Safety factor in any part of that shaft that is marked in red are critical and it needs to be reformed. The probability of failure in red colored parts is very high in long shaft in JD955 combine.

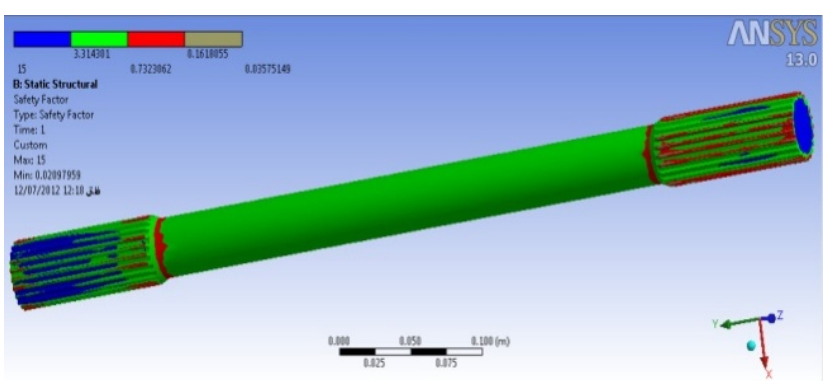

Figure 5. Factor of safety of axle of JD955 in static loading.

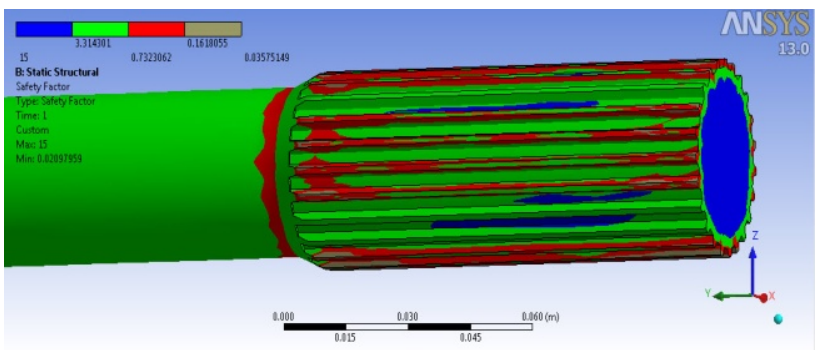

Figure 6. Factor of safety of axle of JD955 in static loading (zoom section)

\section{Conclusion}

In analyzing finite element from the axis of JD955 long shaft under static loading specified that safety factor value is low in parts of the shaft which increases the chance of failure. Safety factor in any part of that shaft that is marked in red are critical and it needs to be reformed. The probability of failure in red colored parts is very high in long shaft in JD955 combine. Obviously, there are the solutions for enhancing safety factor in these areas. Increasing the percentage of some alloys can produce appropriate steel alloy for current work circumstances. Adding some chromium to steel leads to various chromium carbides that are very hard. Produced steel is very shapeable in comparison with the steel has same hardness by adding carbon. Moreover, the existence of chromium in steel results in ordering of grains that it is associated with increased toughness. Chromium increases critical temperature range, for this reason, increasing the percentage of chromium to steel alloy is a low-cost 
recommendation for manufacturers to eliminate the risk of failure.

\section{REFERENCES}

[1] Ayyazi, M. Designing and Fabricating of Platform for JD1165Combine. Master of Science Thesis, Tehran University. 2004.

[2] Azadbakht M., Taghizadeh A. A., Hashemi, A., Janzadeh, G. R. Analysis of Stresses on Straw Walker Crankshaft of John Deere 955 Combine Harvester. Universal Journal of Agricultural Research 1(1): 9-16. 2013.

[3] Beckert, B.A. Venturing into Virtual Product Development,Computer-Aided ngineering, Pp: 45-50. 1996.

[4] Behroozi Lar, M., Jafari, A., Mobli, H. and Shahid Zadeh M. Grain combine harvester. Banke keshavarzi Publication. 2007.

[5] Hancq, D.A. Fatigue Analysis Using ANSYS. ANSYS Inc., pp 22. http://www.ansys.com. 2003.

[6] Lee, K. Principles of CAD/CAM/CAE Ststems. Addison-Wesley, Inc.1999.
[7] Leon, N., P.O. Martinez and Adaya P. Reducing the Weight of a Frontal Axle Beam Using Experimental Test Procedures to Fine Tune FEA, 2nd Worldwide MSC Automotive Conference, Dearborn, Michigan. 2000.

[8] Mahanty, K.D., V. Manohar, B.S. Khomane and S. Nayak. Analysis and Weight Reduction of a Tractor's Front Axle. Tata Consultancy Services, India, Swarup Udgata, International Auto Limited, India. 2001.

[9] Maly, J. and E. Bazzaz. Design Change from Casting to Welding for an Axle Casing. http://WWW.aveng.com/Paper _ MSC_03.pdf. 2003

[10] Rabb, R. Fatigue failure of a connecting rod. J. Eng. Failure Anal., 3: 13-28. 1996.

[11] Ranjbar, I., Gausem zadeh, H. R. and Davoodi, Sh. Engine and tractor power. Tabriz University Publication. 1997.

[12] Saatchi, A. and Edris, H. Steel Key. Arkan Danesh Publication. pp 22. 2010.

[13] Shigley, J. E. and Mischke, C. R. Mechanical EngineeringDesign.5th edn. McGraw-Hill Book Company. 1989.

[14] Zarepoor, Gh. R. Design of machine elements. Danesh negar Publication. 31-32p. 2001. 